\title{
Amount Recovered Infinity Observed Normalized by Body Mass Index
}

National Cancer Institute

\section{Source}

National Cancer Institute. Amount Recovered Infinity Observed Normalized by Body

Mass Index. NCI Thesaurus. Code C112223.

The cumulative amount recovered extrapolated to infinity, calculated using the observed value of the last non-zero concentration, divided by the body mass index. 